\title{
Deregulation of subcellular biometal homeostasis through loss of the metal transporter, Zip7, in a childhood neurodegenerative disorder
}

\author{
Alexandra Grubman', Grace E Lidgerwood', Clare Duncan', Laura Bica', Jiang-Li Tan', Sarah J Parker ',2, \\ Aphrodite Caragounis ${ }^{1}$, Jodi Meyerowitz ${ }^{1}$, Irene Volitakis ${ }^{3}$, Diane Moujalled ${ }^{1}$, Jeffrey R Liddell', James L Hickey ${ }^{4}$, \\ Malcolm Horne ${ }^{3}$, Shoshanah Longmuir ${ }^{3}$, Jari Koistinaho ${ }^{2}$, Paul S Donnelly ${ }^{4}$, Peter J Crouch ${ }^{1,3}$, Imke Tammen $^{5}$, \\ Anthony R White ${ }^{1,3^{*}+}$ and Katja M Kanninen ${ }^{1,2+}$
}

\begin{abstract}
Background: Aberrant biometal metabolism is a key feature of neurodegenerative disorders including Alzheimer's and Parkinson's diseases. Metal modulating compounds are promising therapeutics for neurodegeneration, but their mechanism of action remains poorly understood. Neuronal ceroid lipofuscinoses (NCLs), caused by mutations in CLN genes, are fatal childhood neurodegenerative lysosomal storage diseases without a cure. We previously showed biometal accumulation in ovine and murine models of the CLN6 variant NCL, but the mechanism is unknown. This study extended the concept that alteration of biometal functions is involved in pathology in these disorders, and investigated molecular mechanisms underlying impaired biometal trafficking in CLN6 disease.

Results: We observed significant region-specific biometal accumulation and deregulation of metal trafficking pathways prior to disease onset in CLN6 affected sheep. Substantial progressive loss of the ER/Golgi-resident Zn transporter, Zip7, which colocalized with the disease-associated protein, CLN6, may contribute to the subcellular deregulation of biometal homeostasis in NCLs. Importantly, the metal-complex, Zn"(atsm), induced Zip7 upregulation, promoted Zn redistribution and restored $\mathrm{Zn}$-dependent functions in primary mouse Cln6 deficient neurons and astrocytes.

Conclusions: This study demonstrates the central role of the metal transporter, Zip7, in the aberrant biometal metabolism of CLN6 variants of NCL and further highlights the key contribution of deregulated biometal trafficking to the pathology of neurodegenerative diseases. Importantly, our results suggest that Zn"(atsm) may be a candidate for therapeutic trials for NCLs.
\end{abstract}

Keywords: Biometal homeostasis, Neurodegeneration, Zip7, Neuronal ceroid lipofuscinoses, CLN6

\section{Introduction}

Biometals including $\mathrm{Zn}$ and $\mathrm{Cu}$ are immensely important for brain function. When homeostatic control fails in aging or disease, biometal mislocalization or altered homeostasis can drive pathological changes as observed in patients suffering from neurodegenerative diseases [1], as the brain is especially vulnerable to metal-induced oxidative

\footnotetext{
* Correspondence: arwhite@unimelb.edu.au

${ }^{\dagger}$ Equal contributors

'Department of Pathology, The University of Melbourne, Parkville, VIC 3010,

Australia

${ }^{3}$ Florey Institute of Neuroscience and Mental Health, The University of

Melbourne, Parkville, VIC 3010, Australia

Full list of author information is available at the end of the article
}

stress. Importantly, even subtle changes to biometal concentrations have been associated with significant neuronal pathology [2].

Neuronal ceroid lipofuscinoses (NCLs), commonly known as Batten diseases, are a genetically heterogeneous group of lysosomal storage diseases (LSDs) [3], characterized by storage of lipofuscin material in lysosome-derived fluorescent storage bodies $[4,5]$ and neuronal demise leading to progressive loss of vision, motor dysfunction and premature death [6]. Oxidative stress and neuroinflammation phenotypes in NCLs are reminiscent of other forms of neurodegeneration. Alternative mutations in the metal transporter ATP13a2

\section{Biomed Central}


have been implicated in an NCL and early onset Parkinsonism, suggesting a common pathway [7-11], however the functions of the NCL proteins and underlying disease processes are not well understood. A variant late infantile and an adult onset NCL are caused by mutations in CLN6, which encodes a highly conserved transmembrane endoplasmic reticulum (ER) protein of unknown function $[12,13]$.

We previously demonstrated region-specific alterations to biometal homeostasis in ovine CLN6 disease that correlated with the development of neurodegeneration [14]. Moreover, biometal accumulation was associated with region-specific loss of $C \ln 6$ mRNA in presymptomatic Cln6 affected mice [15]. However, the mechanisms responsible for these changes remain unknown. Here we show that altered biometal trafficking pathways involve loss of ER-co-localized transmembrane proteins, CLN6 and the metal transporter Zip7, triggering subcellular metal accumulation in presymptomatic CLN6 disease. Moreover, correction of impaired metal-dependent functions in $C \ln 6$ cells is achieved via up-regulation of Zip7 by a cell permeable metal complex, $\mathrm{Zn}^{\mathrm{II}}$ (atsm). These studies demonstrate the potential of biometal modulation for the development of therapeutics for CLN6 disease.

\section{Materials and methods}

\section{Sheep}

The CLN6 Merino and South Hampshire research flocks were maintained under standard pasture conditions on University research farms and genotyped as described [16]. As previously reported, Merino CLN6 sheep are phenotypically normal until the age of 8-12 months [17]. From approximately 8 months, the affected sheep exhibit mild behavioural changes and visual impairment, which progress throughout disease course, resulting in premature death between 19 to 27 months of age [17]. Similar to the South Hampshire CLN6 model, the affected Merino sheep brains do not develop normally to maturity and begin to atrophy from approximately 6 months of age. The genotype of Merino sheep was determined by genotyping for the disease causing c.184C > T mutation in the CLN6 gene [18]. Homozygous normal animals were used as controls. CLN6 South Hampshire sheep were used as an additional model of CLN6 disease. For comparison to affected CLN6 South Hampshire sheep, we used unaffected homozygous controls. As an additional control group, we used unaffected heterozygous CLN5 Borderdale sheep, as previously described [19]. All animal procedures were carried out according to NIH guidelines, the NSW Animal Research Act (1985), the New Zealand Animal Welfare Act (1999), and the Australian Code of Practice for the Care and Use of Animals for Scientific Purposes 7th Edition (NHMRC 2004). Brain and peripheral samples were collected from 3, 7 and 14 month-old control and
CLN6 affected Merino sheep, 12-14 month-old control and CLN6 affected South Hampshire sheep and unaffected CLN5 heterozygote Borderdale sheep. At post mortem, brains were dissected into the following regions: occipital lobe, parietal lobe, frontal lobe, thalamus, cerebellum and brain stem, and immediately frozen. Liver and muscle (rectus femoris) tissue was also collected for analysis.

\section{Mice}

Animal handling and experimentation were performed in accordance with national and institutional guidelines (University of Melbourne AEC no. 1112024). The genotypes of affected Cln6 mice [20] (B6.Cg-Cln6nclf/J, The Jackson Laboratory) were determined as previously described [15]. Mice were euthanized by $\mathrm{CO}_{2}$ asphyxiation or cervical dislocation, as appropriate.

\section{Cell culture}

Primary cortical neuronal cultures were established from embryonic day 14 (E14) mice, and primary astrocytes were harvested from neonatal mice as previously described [21]. For primary cortical cultures, E14 mouse cortices were removed, dissected free of meninges and dissociated in $0.025 \%$ trypsin. Viable dissociated cells were suspended in Minimum Eagle's Medium supplemented with 10\% fetal bovine serum (FBS), 5\% horse serum, 1\% glutamine, and $10 \mu \mathrm{g} / \mathrm{mL}$ gentamicin, plated into Poly-D-lysine coated culture plates, and incubated at $37^{\circ} \mathrm{C}$ in $5 \% \mathrm{CO}_{2}$. Growth medium was replaced with Neurobasal growth medium supplemented with B27, glutamine and gentamicin the following day. 3-4 days after plating, half of the media was replaced with fresh Neurobasal media. Cells were used for experiments 6 days after plating.

For astrocyte culture, newborn mice were decapitated, the brains removed and placed into ice-cold preparation buffer (containing $68 \mathrm{mM} \mathrm{NaCl}, 2.7 \mathrm{mM} \mathrm{KCl}, 110 \mu \mathrm{M}$ $\mathrm{KH}_{2} \mathrm{PO}_{4}, 84.5 \mu \mathrm{M} \mathrm{Na} \mathrm{HPO}_{4}, 29 \mathrm{mM}$ sucrose, $2.8 \mathrm{mM}$ glucose, $20 \mathrm{U} / \mathrm{mL}$ penicillin and $34.4 \mathrm{pM}$ streptomycin). Brains were diced, then sequentially passed through $250 \mu \mathrm{m}$ and $135 \mu \mathrm{m}$ gauze and centrifuged at $500 \times \mathrm{g}$ for $5 \mathrm{~min}$. Cell pellets were resuspended in growth medium (high glucose DMEM containing 10\% FCS, 20U/mL penicillin and $34.4 \mathrm{pM}$ streptomycin) and plated into 6 well plates at $1.5 \times 10^{6}$ cells/well. Cells were maintained at $37^{\circ} \mathrm{C}$ with $10 \% \mathrm{CO}_{2}$. Growth medium was replaced every 7 days, and experiments were performed after 16 days in vitro.

$\mathrm{Zn}^{\mathrm{II}}$ (atsm) was added to cells cultured in Neurobasal medium for neurons or high glucose DMEM (Life Technologies) containing 10\% FCS, $20 \mathrm{U} / \mathrm{mL}$ penicillin and 34.3pM streptomycin for astrocytes. High content screening analysis was used to visualize and quantitate neurite characteristics of primary neurons, as described in supplementary methods. 


\section{Metal analyses}

The metal contents in sheep occipital, parietal and frontal lobes, cerebellum, thalamus, brainstem, liver and muscle were measured using inductively coupled plasma massspectrometry (ICP-MS) as before [14].

\section{Cathepsin D assay}

Cathepsin D activity was measured using a Fluorometric cathepsin D activity assay kit (Abcam, Cambridge, MA).

\section{Alkaline phosphatase (ALP) assay}

ALP activity assays were performed on primary mouse astrocytes, as described [22], $p$-nitrophenol release being measured at $405 \mathrm{~nm}$ over $30 \mathrm{~min}$ using shrimp ALP (Sigma-Aldrich, Castle Hill, NSW, Australia) as a standard.

\section{FluoZin-3 fluorescence}

Mouse neurons were pre-treated with $5 \mu \mathrm{M}$ FluoZin-3 (Life Technologies) for $30 \mathrm{~min}$, followed by a $30 \mathrm{~min}$ washout. Fluorescence was measured with an Enspire plate reader (PerkinElmer, Glen Waverley, Victoria, Australia) in well scan mode at excitation and emission wavelengths of 494 and $516 \mathrm{~nm}$, respectively.

\section{High content screening analysis}

Primary cortical mouse neurons plated in clear bottom Costar 96 well plates (Corning, Tewksbury, MA) were treated with $\mathrm{Zn}^{\mathrm{II}}$ (atsm) [23] for $1 \mathrm{~h}$, at the concentrations indicated. Cells were fixed for $15 \mathrm{~min}$ in $4 \%$ PFA in phosphate buffered saline (PBS), permeabilised for $10 \mathrm{~min}$ at $-20^{\circ} \mathrm{C}$ with ice-cold $100 \%$ methanol, and blocked with 5\% FCS and 0.03\% Triton-X100 in PBS. Zip7 complexes were detected with rabbit $\alpha$-Zip7 (1:500; ProteinTech, Chicago, IL) in dilution buffer (1\% BSA, 0.03\% TritonX100 in PBS) and goat- $\alpha$-rabbit IgG AlexaFluor 647 (1:500, Life Technologies). Cell nuclei were stained with DAPI (1.5 $\mu \mathrm{M}$, Life Technologies). For the measurement of neurite lengths, cellular tubulin was stained with rabbit $\alpha$-tubulin antibodies (1:50; Cell Signaling, Arundel, Queensland, Australia). Staining in cells was viewed with a Cellomics ArrayScan VTI HCS Reader (Thermo Scientific, Scoresby, Victoria, Australia). The Cellomics ArrayScan VTI HCS Reader is a high throughput microscopy-based screening analysis platform, which provides highly reproducible quantitative and qualitative data that can be obtained from cell populations in 96 well plate format. Due to rapid data acquisition, the ability to measure 1000s of cells per treatment condition and lack of experimenter bias, the Cellomics technology is now well accepted for routine use in neurite outgrowth assays, as evidenced by a number of highly cited publications [24-26]. At least 1,000 cells or 20 fields per well were captured with the $20 \times$ objective. Data were analyzed with vHCS 116
Discovery Toolbox software (Thermo Scientific), using the compartmental analysis or neuronal profiling bioapplications, as appropriate (Additional file 1). For analysis of Zip7 staining intensity, the nucleus was identified by DAPI staining using the vHCS 116 Discovery Toolbox software. The perinuclear region of each cell was designated as beginning $2 \mu \mathrm{m}$ from the perimeter of the nucleus, and extending for a $2 \mu \mathrm{m}$ radius around the nucleus. The average pixel intensity of this region was calculated and plotted for at least 1000 cells per well, performed in triplicate wells. The experiment was repeated 4 times with similar results.

\section{Immunofluorescent staining}

Immunofluorescent staining was performed as previously described [27]. Briefly, primary cortical mouse neurons were seeded onto coverslips in 24 well plates, treated with $\mathrm{Zn}^{\mathrm{II}}$ (atsm) for $4 \mathrm{~h}$, fixed in $4 \%$ PFA, permeabilised in $0.1 \%$ Triton-X100 in PBS, and blocked in 5\% FCS in PBS. Zip7 was detected using polyclonal rabbit- $\alpha$-Zip7 antibodies (1:500), and goat- $\alpha$-rabbit AlexaFluor 488 (1:500; Life Technologies). Cell nuclei were visualized with DAPI. Coverslips were mounted onto microscope slides with fluorescence mounting media (DAKO, Campbellfield, Victoria, Australia) and visualized with a Leica DMIRB fluorescence microscope. For colocalization studies, primary mouse cortical neurons were reacted with rabbit primary anti-CLN6 and goat primary anti-Zip7 antibodies. Anti-goat AlexaFluor-488 and anti-rabbit AlexaFluor-568 dye labeled secondary antibodies were used to reveal Zip7 and CLN6 expression, respectively. ER localization was determined by staining with the rabbit polyclonal antibodies to the ER marker, calnexin (1:100; Abcam) and anti-rabbit AlexaFluor-568 dye labeled secondary antibodies. Fluorescence was visualized by confocal microscopy using the Zeiss Meta confocal scanning laser microscope with a magnification of 40x.

\section{qRT-PCR}

RNA was prepared from $10^{6}$ primary mouse neuronal cells using the MagMax Total RNA isolation kit (Life Technologies). RNA (200 ng) was reverse transcribed using the High Capacity cDNA kit (Life Technologies). TaqMan gene expression assays for $M T 1 A$ and TUBA8 were purchased from Life Technologies (Mm00496660_g1 and Mm00833707_mH, respectively) and qRT-PCR was performed as previously described [15]. Delta $\mathrm{Ct}$ method was used for normalization of expression relative to $\beta$-tubulin.

\section{siRNA transfection}

Mouse NIH 3T3 cells $\left(6 \times 10^{5} / \mathrm{mm}^{2}\right)$ were cultured for $24 \mathrm{~h}$ in DMEM supplemented with $10 \%$ FBS, $1 \% 20 \mathrm{U} / \mathrm{mL}$ 
penicillin, 34.4pM streptomycin, 1\% L-Glutamine, 1\% HEPES and $1 \%$ non essential amino acids. Transfection was achieved with DharmaFECT transfection reagent 4 (Thermo Scientific) and $100 \mathrm{nM}$ Stealth Select RNAi siRNA specific to Zip7 (oligo ID MSS205001) or Negative control High GC siRNA (both from Life Technologies) according to manufacturer specifications. siRNA-transfection reagent complexes were incubated for $20 \mathrm{~min}$ in DMEM prior to dropwise addition to cells. Cell media was changed after $24 \mathrm{~h}$ to DMEM containing 10\% FBS. $72 \mathrm{~h}$ after transfection, cells were harvested for Western blotting by scraping and centrifugation $(18,000 \times \mathrm{g}, 5 \mathrm{~min})$.

\section{Western blotting}

Cell lysates and tissues homogenized with a Dounce tissue grinder were extracted with Phosphosafe (Merck, Kilsyth, Victoria, Australia) containing a protease inhibitor cocktail (Roche, Castle Hill, NSW, Australia) and DNAse (Roche). The protein concentrations of supernatants after centrifugation $\left(12,000 \times \mathrm{g}, 5 \mathrm{~min}, 4^{\circ} \mathrm{C}\right)$ were measured with the BCA assay kit (Pierce) according to manufacturer's instructions. Equal protein amounts were separated on 12\% SDS-PAGE Tris-glycine or 4-12\% Bis-Tris gels (Life Technologies), as appropriate. Proteins were transferred to PVDF membranes and blocked with $4 \%$ skim milk solution in PBS-Tween. Membranes were probed overnight with primary antibodies diluted in $4 \%$ skim milk solution in PBS-Tween. Unless stated otherwise, primary antibodies were raised in rabbits and were diluted 1:1000. The antibodies used in this study were directed against: CLN6 (kindly provided by Dr. Sara Mole, University College London), mouse Zip3 (Abnova), Zip7 (1:2000, Proteintech), Zip8 (1:1200, Proteintech), Zip14 (Novus), ZnT1 (Sigma), ZnT3 (Proteintech), ZnT6 (1:1200, Proteintech), ZnT7 (Proteintech), mouse $\alpha$ synuclein (1:2000, kindly provided by Professor Malcolm Horne, The Florey Institute of Neurosciences), V-ATPase (GenScript), as well as the phosphorylated form of GSK-3 (Cell Signaling Technologies). The horseradish peroxidase-conjugated anti-mouse or anti-rabbit secondary antibodies (Cell Signaling Technologies) were used at a dilution of 1:5000. Membranes were developed by chemiluminescence (Amersham ECL Advance Western blotting detection kit) and imaged on a Fujifilm LAS3000 Imager (Berthold). Western blots were subjected to densitometry analysis using Image J software.

Target band intensities were compared to control bands (ImageJ, Bethesda, MD) on blots probed with antibodies against GAPDH, $\beta$-tubulin, total Akt or total ERK used as controls to normalize protein concentrations in CLN6 affected and control animals.

\section{Statistical analyses}

Differences in metal content, gene expression, protein concentrations, ALP activities and neurite characteristics were determined using unpaired Student's $t$-tests. $p$ values below 0.05 were considered significant. Data are expressed as means \pm SEM and are representative of a minimum of three independent experiments. Where sheep data are presented, $\mathrm{N}=$ three or four animals per group. Pearson correlation coefficients were used to determine the strength of correlation between Zn, P-GSK, metallothionein, CLN6 and Zip7 levels in individual sheep.

\section{Results}

Impaired lysosomal function and neurodegenerationassociated proteinopathy in NCLs

Lysosomal dysfunction, prior to the onset of clinical signs in CLN6 affected Merino sheep, which occurs at 8-12 months [17], was demonstrated by reduced cathepsin D activity from 3 months of age (Figure 1A). An agedependent reduction of subunit B2 of V-ATPase was also observed in the occipital lobe, the site of initial neuropathological changes of South Hampshire CLN6 sheep (Figure 1B) [28], suggestive of defects in lysosomal functionality [29]. Due to the close relationship between NCLs and Parkinson's disease, we examined the levels of Parkinson's disease proteins, $\alpha$-synuclein, and the metal transporter, ATP13a2. Significantly increased concentrations of the high molecular weight form of $\alpha$-synuclein [30] and a trend toward increased ATP13a2 levels ( $p=$ 0.1782 ) were also observed after onset of neurological disease (Figure 1C-D), providing further support for a relationship between Parkinson's and NCL diseases.

\section{Biometals accumulate in preclinical CLN6 sheep}

We previously reported accumulation of $\mathrm{Zn}, \mathrm{Mn}$, Co and $\mathrm{Cu}$ in disease-affected brain regions of CLN6 Merino and South Hampshire sheep after the onset of clinical signs [14]. To investigate biometal changes in early NCL pathology, we determined metal concentrations in 3 and 7 month old normal and affected Merino sheep (Table 1). Zn concentrations were higher in the parietal lobe and muscle of affected sheep at 7 months of age, but lower in the liver of 3 month-old and plasma of 7 month-old affected sheep. Liver Mn concentrations were substantially reduced, and plasma Co reduced at 3 and 7 months of age (Additional file 2). $\mathrm{Cu}$ concentrations in the occipital and frontal lobes were higher in affected animals at both ages while those in the parietal lobe, brainstem and cerebellum where higher than control values at 3 months but lower at 7 months. Increased $\mathrm{Cu}$ concentrations were also observed in the liver of 3 and 7 month old CLN6 sheep. Together, these data indicate that disturbances to biometal homeostasis may precede detectable clinical signs in CLN6 disease. Moreover, biometal alterations not only occur in the central nervous system (CNS), but also peripherally in NCL affected animals. 

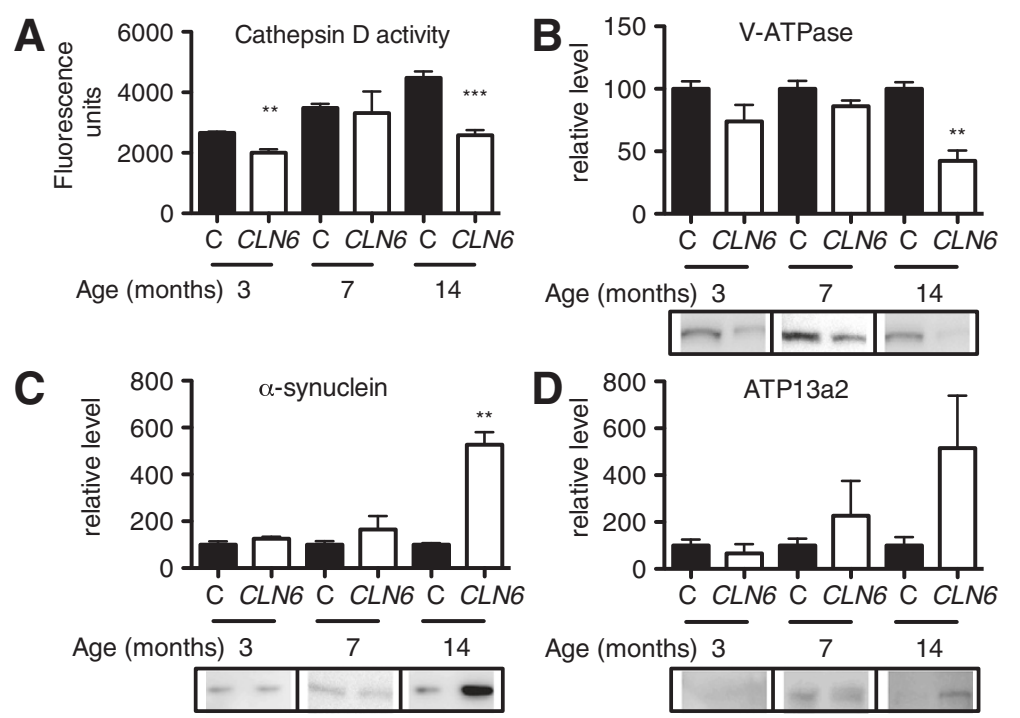

Figure 1 Lysosomal dysfunction and increased a-synuclein concentrations in CLN6 sheep. (A) Cathepsin D activity was measured in homogenates $(1 \mu \mathrm{g})$ isolated from the occipital lobe of 3,7 and 14 month old control or CLN6 affected Merino sheep ( $N=3$ per group) using a fluorometric Cathepsin D activity assay. (B-D) Densitometry and representative immunoblots of homogenates $(5-40 \mu \mathrm{g})$ isolated from the occipital lobe of 3, 7 and 14 month old control or CLN6 affected sheep probed with antibodies directed against V-ATPase (B), a-synuclein (C) or ATP13a2 (D). GAPDH was used as a loading control. Quantification was performed in ImageJ and concentrations are expressed relative to those in control sheep at each age. Data are mean + SEM. ${ }^{* *} p<0.01,{ }^{* * *} p<0.001$ by Student's $t$ test. $\mathbf{C}$, control.

Table 1 Increased biometal concentrations in the brain of preclinical CLN6 Merino sheep

\begin{tabular}{|c|c|c|c|c|c|}
\hline & \multirow[b]{2}{*}{ Age } & \multicolumn{2}{|l|}{$\mathrm{Zn}^{\mathrm{a}}$} & \multicolumn{2}{|l|}{$\mathrm{Cu}^{\mathrm{a}}$} \\
\hline & & Control & CLN6 & Control & CLN6 \\
\hline \multirow{2}{*}{ Frontal } & 3 & $11.1 \pm 0.2$ & $11.1 \pm 0.7$ & $2.0 \pm 0.2$ & $2.3 \pm 0.2^{*}$ \\
\hline & 7 & $11.4 \pm 0.2$ & $12.1 \pm 1.4$ & $2.2 \pm 0.3$ & $2.7 \pm 0.6$ \\
\hline \multirow{2}{*}{ Occipital } & 3 & $11.2 \pm 0.4$ & $11.2 \pm 1.2$ & $2.2 \pm 0.5$ & $2.8 \pm 0.3^{*}$ \\
\hline & 7 & $13.1 \pm 0.5$ & $13.9 \pm 1.9$ & $2.5 \pm 0.2$ & $3.4 \pm 0.9^{*}$ \\
\hline \multirow{2}{*}{ Parietal } & 3 & $10.7 \pm 0.9$ & $11.0 \pm 0.4$ & $1.8 \pm 0.3$ & $2.5 \pm 0.1 \wedge$ \\
\hline & 7 & $12.9 \pm 0.6$ & $13.6 \pm 0.4^{*}$ & $2.5 \pm 0.4$ & $2.1 \pm 0.3$ \\
\hline \multirow{2}{*}{ Thalamus } & 3 & $10.7 \pm 1.3$ & $10.5 \pm 0.6$ & $2.1 \pm 0.4$ & $1.8 \pm 0.1$ \\
\hline & 7 & $10.6 \pm 1.0$ & $11.6 \pm 1.3$ & $2.7 \pm 1.2$ & $2.7 \pm 1.3$ \\
\hline \multirow{2}{*}{ Cerebellum } & 3 & $12.2 \pm 1.1$ & $12.5 \pm 1.3$ & $2.8 \pm 0.4$ & $3.0 \pm 0.5$ \\
\hline & 7 & $11.4 \pm 0.5$ & $11.6 \pm 0.5$ & $3.4 \pm 0.5$ & $2.3 \pm 0.4 \wedge$ \\
\hline \multirow{2}{*}{ Brainstem } & 3 & $11.2 \pm 1.0$ & $11.7 \pm 0.6$ & $2.5 \pm 0.3$ & $2.8 \pm 0.3^{*}$ \\
\hline & 7 & $8.52 \pm 0.8$ & $9.2 \pm 0.4$ & $1.9 \pm 0.2$ & $1.5 \pm 0.4$ \\
\hline \multirow{2}{*}{ Liver } & 3 & $53.9 \pm 18.5$ & $36.3 \pm 9.2^{*}$ & $20.2 \pm 2.6$ & $37.1 \pm 1.6^{\#}$ \\
\hline & 7 & $28.1 \pm 5.3$ & $29.5 \pm 3.0$ & $40.4 \pm 7.7$ & $58.2 \pm 6.5^{\#}$ \\
\hline \multirow{2}{*}{ Muscle } & 3 & $22.0 \pm 4.5$ & $21.5 \pm 1.9$ & $0.6 \pm 0.4$ & $0.5 \pm 0.2$ \\
\hline & 7 & $19.9 \pm 3.0$ & $27.3 \pm 4.1^{\wedge}$ & $0.2 \pm 0.1$ & $0.3 \pm 0.2$ \\
\hline \multirow{2}{*}{ Plasma } & 3 & $11.7 \pm 1.1$ & $12.0 \pm 2.1$ & $13.6 \pm 2.0$ & $14.3 \pm 2.7$ \\
\hline & 7 & $14.0 \pm 1.4$ & $10.5 \pm 1.8^{*}$ & $12.8 \pm 1.1$ & $10.2 \pm 2.2$ \\
\hline
\end{tabular}

${ }^{a}$ Metal concentrations in the CNS and peripheral tissues of 3 and 7 month old control and CLN6 Merino sheep were measured using ICP-MS. The concentrations of $\mathrm{Zn}$ and $\mathrm{Cu}$ in each tissue are expressed as mean \pm S.D. Values correspond to $\mu \mathrm{g} \mathrm{metal} / \mathrm{g}$ tissue. ${ }^{*} p<0.05, \wedge p<0.01,{ }^{*} p<0.001$ by Student's $t$ test.
Region-specific alterations to biometal trafficking pathways are associated with loss of CLN6

Western blotting revealed an age related decline in the relative amount of CLN6 in the affected occipital lobe, resulting in very low levels at 14 months (Figure 2A). We assessed the expression levels of the $\mathrm{Cu}$ transporters, CTR1, ATP7A, ATP7B, but observed no differences in expression of these proteins between control and CLN6 Merino sheep (unpublished data). We next focused on Zip and ZnT metal transporter proteins, initially identified for $\mathrm{Zn}$ transport and reported to transport different subsets of the biometals altered in CLN6 affected sheep [31-35]. The ER/Golgi-resident transporter, Zip7, was progressively lost in the affected occipital lobe in an agedependent manner from 3 months, reaching statistical significance from 7 months (Figure 2B, full blot of Zip7 shown in Additional file 3). Significantly reduced expression of Zip8, Zip14 and ZnT7 in affected Merino sheep was apparent by 14 months of age (Figure $2 \mathrm{C}-\mathrm{E}$ ), whereas ZnT1, ZnT3 and ZnT6 concentrations were relatively unchanged (Additional file 4). Similar alterations to the concentrations of metal trafficking proteins were also observed in 12 month-old CLN6 affected South Hampshire sheep, except that ZnT6 expression was reduced, while ZnT7 expression was unaffected in this model (Additional file 5). The $\mathrm{Zn}$ and $\mathrm{Cu}$ sequestering protein, metallothionein (MT), was upregulated $\sim 40$ fold in Merino CLN6 sheep at 14 months of age (Figure 2F) 

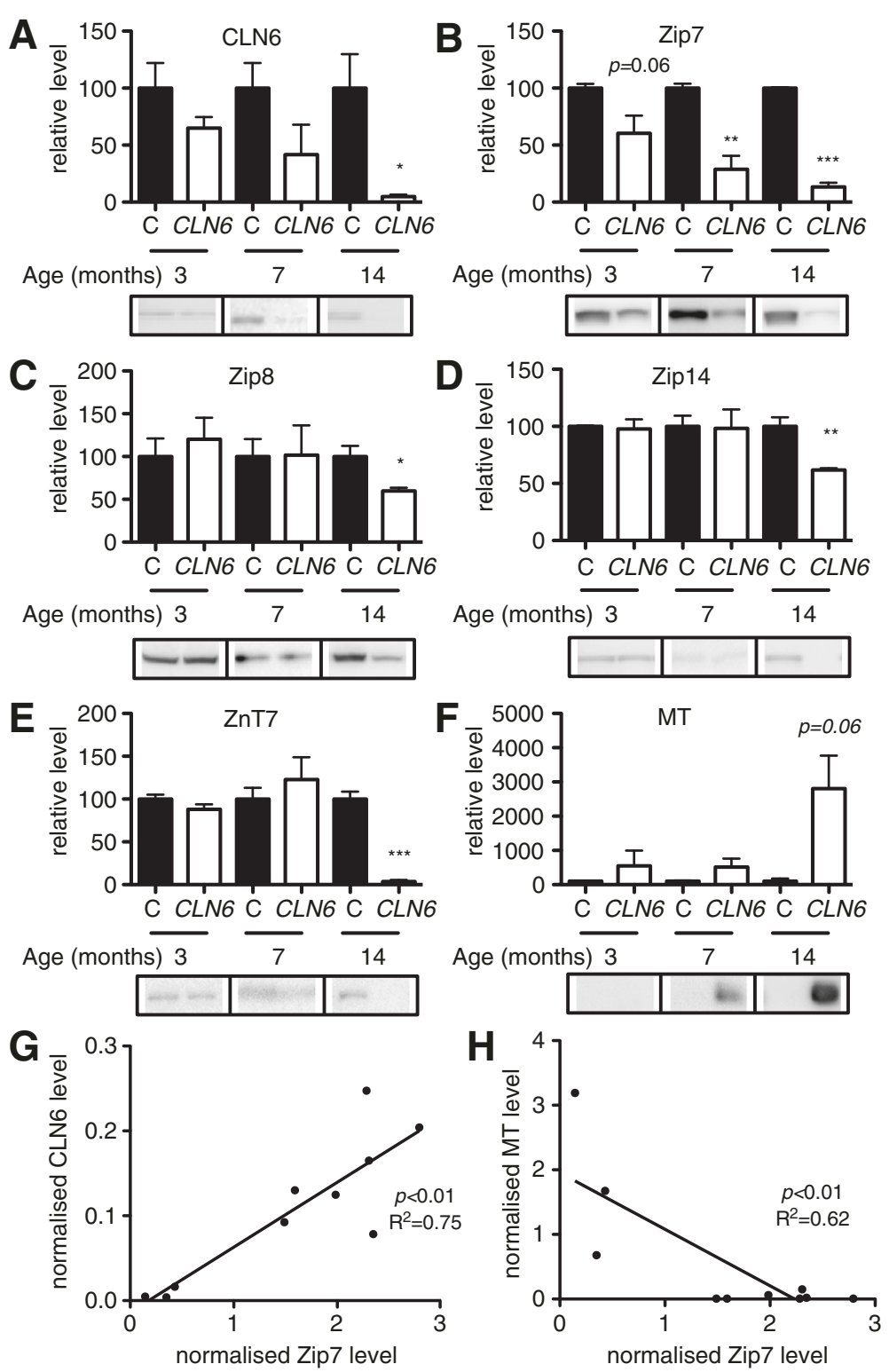

Figure 2 Altered biometal trafficking pathways are associated with loss of CLN6 in sheep. (A-F) Densitometry and representative immunoblots of homogenates $(5-40 \mu \mathrm{g}$ ) isolated from the occipital lobe of 3,7 and 14 month old control or CLN6 affected sheep ( $N=3$ per group) probed with antibodies directed against CLN6 or a range of metal transporters or metal binding proteins. GAPDH, $\beta$-tubulin, total Akt or total ERK, as appropriate, were used as loading controls. Quantification was performed in ImageJ and levels are expressed relative to those in control sheep at each age. Data are mean + SEM. ${ }^{*} p<0.05,{ }^{* *} p<0.01,{ }^{* * *} p<0.001$ by Student's $t$ test. C, control. (G-H) Normalized Zip7 protein levels in Merino sheep occipital lobe were plotted against normalized levels of CLN6 (G) or MT (H) to determine correlations between these proteins. Linear regression analysis was performed in GraphPad Prism.

consistent with CLN6 affected South Hampshire sheep, as reported [14]. Correlation analysis revealed a strong positive relationship between the levels of Zip7 and CLN6 and a strong negative correlation between Zip7 and MT levels in individual sheep (Figure 2G-H).

In addition to the occipital lobe, a significant decrease in Zip7 occurred in the frontal and parietal lobes of CLN6 affected Merino sheep by 14 months of age (Additional file 6). Significant reductions were also observed in the cerebellum and thalamus of similarly aged CLN6 affected South Hampshire sheep (Additional file 7B-C), indicating that reduction of Zip7 occurs throughout the brain in both breeds of sheep.

Brain $\mathrm{Zn}$ is aberrantly elevated in sucrose density gradient fractions corresponding to the ER and Golgi in Cln6 mouse brains [15]. We therefore investigated whether deregulation of subcellular biometal homeostasis also occurred in CLN6 sheep. To investigate early changes, before substantial 
changes to bulk metal levels were evident, we analyzed occipital lobes from 3-month old control and CLN6 affected Merino sheep (Figure 3). Subcellular distribution profiles of $\mathrm{Zn}$ and $\mathrm{Cu}$ were significantly altered, with increased $\mathrm{Zn}$ and $\mathrm{Cu}$ in the lighter fractions (fractions 1-7) of CLN6 affected brains (Figure 3A-B). Interestingly, Zip7 is lost in these fractions in CLN6 affected brains (Figure 3C), consistent with retention of excess metals in those fractions in CLN6 animals. We also probed fractions for CLN6, but were unable to detect CLN6 protein in any fraction (unpublished data).

\section{Cln6 neurons display defects in Cln6 transcription and perinuclear Zip7 staining}

Given the challenges of in vitro studies in sheep, we further investigated the role of Zip7 in CLN6 disease using mice carrying a natural mutation in $C \ln 6$ [20]. $C \ln 6$ mRNA expression (Figure 4A) and perinuclear Zip7 staining (Figure 4B,D) were significantly reduced in neurons cultured from $C \ln 6$ mutant mice. To investigate whether reduced Zip7 expression was associated with elevated labile $\mathrm{Zn}$ content, we used a cell-permeable $\mathrm{Zn}$-binding fluorophore, FluoZin-3, which senses $\mathrm{Zn}$ that is not tightly protein-bound $\left(K_{d}=15 \mathrm{nM}\right)$. Consistent with a defect in Zip7-mediated trafficking, readily exchangeable Zn pools were substantially increased in neurons harvested from Cln6 affected mice (Figure 4C). The possibility that the
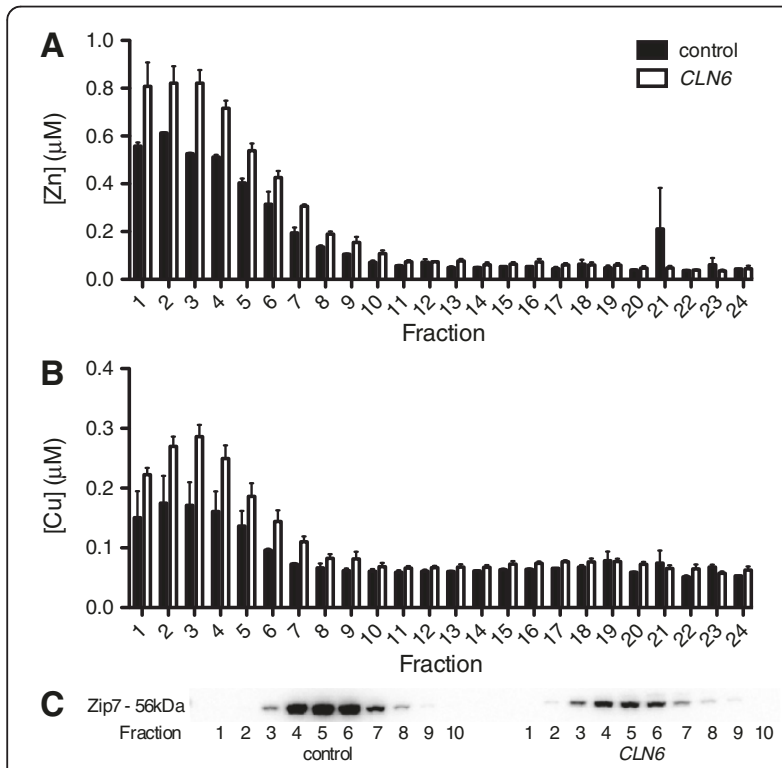

Figure 3 Biometals accumulate in subcellular fractions that display Zip7 loss in presymptomatic CLN6 sheep occipital lobe. Sucrose density gradient fractions from 3 month old sheep occipital lobe were analyzed for metal content by ICP-MS. Data are expressed as the mean + SEM of Zn (A) and Cu (B) concentrations in CLN6 brains (white bars throughout) and control brains (black bars throughout) from 3 individual sheep per genotype. (C) Representative immunoblot of Zip7 protein present in fractions from control and CLN6 affected sheep brains.
ER-localized transmembrane Zip7 and CLN6 [13,36], associate was explored through confocal immunofluorescence. Cortical neurons were co-labeled with antibodies to Zip7 (Figure 5B) and CLN6 (Figure 5C). Perinuclear and punctate staining was observed throughout the cell body and neurites, suggestive of ER/Golgi localization. Importantly, a degree of colocalization between CLN6 and Zip7 was observed (Figure 5D), indicating that these proteins may associate in punctate structures throughout the cell. Co-localization of Zip7 with the ER marker, calnexin, verified that Zip7 was at least partially ER-localized (Additional file 8). These results indicate that loss of Zip7 is detectable in mice prior to birth, and provide support for an association between Zip7 and CLN6 disease.

\section{Delivery of bioavailable $\mathrm{Zn}$ restores $\mathrm{Zn}$-dependent phenotypes through upregulation of Zip7}

Therapeutic modulation of biometal homeostasis has demonstrated promise in the treatment of neurodegenerative disorders [37-39]. Although bulk analysis suggested overall metal accumulation in CLN6 disease, loss of the ER to cytoplasmic metal importer, Zip7, would ultimately drive metal mislocalization to the ER, as previously observed for $\mathrm{Zn}$ in $\mathrm{Cln} 6$ mutant mouse brain [15], and may induce deficiencies of bioavailable metals elsewhere in the cell. Membrane-permeable complexes that deliver bioavailable metals may therefore bypass the Zip7 defects in $C \ln 6$ cells. In light of this, $\mathrm{Zn}$ was delivered using the cell-permeable metallo-complex $\mathrm{Zn}^{\text {II }}$ (atsm) [40]. $\mathrm{Zn}^{\mathrm{II}}$ (atsm) treatment significantly decreased the readily exchangeable $\mathrm{Zn}$ pool in primary $\mathrm{Cln} 6$ neurons, as measured by FluoZin-3 fluorescence (Figure 6A). The apparent paradox of delivering $\mathrm{Zn}$ but observing reduced FluoZin-3 fluorescence is likely to occur via $\mathrm{Zn}^{\mathrm{II}}$ (atsm)-dependent upregulation of MT (Figure 6B), and therefore sequestration of excess labile $\mathrm{Zn} \mathrm{[41].} \mathrm{The} \mathrm{re-}$ sults support abnormal compartmental $\mathrm{Zn}$ levels in $\mathrm{Cln} 6$ affected cells due to Zip7 loss and the ability of $\mathrm{Zn}^{\mathrm{II}}$ (atsm) to at least partially rectify this by up-regulation of MT. As increased labile Zn can trigger neurite outgrowth [42], we next examined the neurite characteristics of $C \ln 6$ neurons. Indeed, $\mathrm{Cln} 6$ cells displayed longer, more extensively branched neurites, which were retracted upon

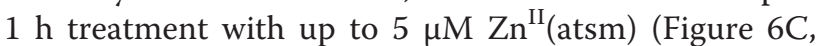
Additional file 1). Together, these data suggest that $\mathrm{Zn}^{\mathrm{II}}$ (atsm) restores metal homeostasis in Cln6 primary neurons.

Although it is neurons that degenerate in NCL disease, astrocytes are severely affected prior to disease onset in both sheep and mouse NCL models $[43,44]$. We therefore also examined a range of $\mathrm{Zn}$-dependent activities in primary astrocytic cultures. We measured the activity of alkaline phosphatase (ALP), a Zn-dependent cytoplasmic 

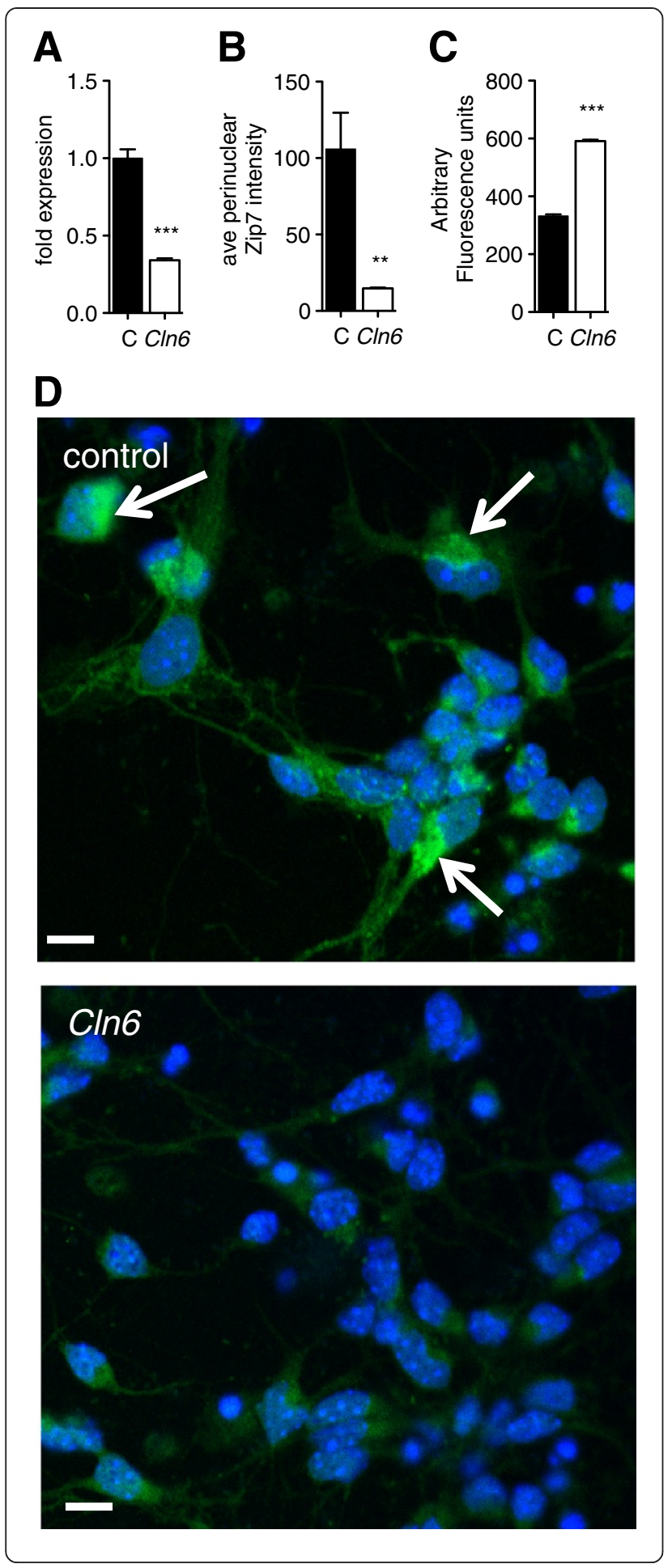

Figure 4 Cln6 cortical neurons display reduced Cln6 transcripts and Zip7 staining with increased labile $\mathrm{Zn}$ accumulation. (A) Cln6 mRNA expression in primary murine cortical neurons was measured using qRT-PCR. Expression values were normalized to tubulin using the delta Ct method. All data are mean + SEM. (B) Zip7 expression was assessed by immunofluorescence. Zip7 was labeled with rabbit Zip7 antibodies and AlexaFluor conjugated anti-rabbit antibodies. Nuclei were stained with DAPI. Quantitative analysis of Zip7 perinuclear distribution was performed using the ArrayScan reader in conjunction with the compartmental analysis software on $>1000$ cells per genotype. (C) Labile Zn in control and CIn6 cortical neurons was measured by FluoZin-3 fluorescence. (D) Zip7 immunofluorescence images are representative of 3 experiments performed on triplicate coverslips. Scale bars represent $10 \mu \mathrm{m}$.

enzyme requiring $\mathrm{Zn}$ loading by ZnT5 and ZnT7 for full activity [45]. Reduced ALP activity in $C \ln 6$ astrocytes was indicative of regional $\mathrm{Zn}$ depletion, but was restored by $1 \mu \mathrm{M} \mathrm{Zn}{ }^{\mathrm{II}}($ atsm) treatment (Figure $6 \mathrm{D}$ ). Elevated labile $\mathrm{Zn}$ can result in aberrant GSK3 phosphorylation [46], evident in CLN6 sheep [14] and primary $C \ln 6$ mouse astrocytes (Figure 6E). $\mathrm{Zn}^{\mathrm{II}}$ (atsm)-dependent rescue of hyperphosphorylated GSK-3 in $C \ln 6$ astrocytes was associated with increased Zip7 (Figure 6E) demonstrating a link between Zn, GSK3 and Zip7 expression. Together the data suggest complex deregulation of subcellular $\mathrm{Zn}$ pools in $\mathrm{Cln} 6$ cells - increased labile $\mathrm{Zn}$ in specific sub-cellular regions and reduced bioavailable $\mathrm{Zn}$ in alternative compartments required for enzyme functions. Importantly, our data show a strong in vitro protective effect of $\mathrm{Zn}^{\mathrm{II}}$ (atsm) on $\mathrm{Zn}$ mislocalization caused by $C \ln 6$ mutation. Interestingly, Zip7 levels in individual sheep were inversely correlated to levels of P-GSK3 and $\mathrm{Zn}$ (Figure 6F-G), supporting functional or regulatory relationships between these proteins and cellular $\mathrm{Zn}$ concentrations. Consistent with a role for Zip7 in this process, siRNA knockdown of Zip7 in mouse NIH 3T3 cells resulted in hyperphosphorylation of GSK3 (Figure 6H-J). These data provide further support for a role of Zip7 in homeostatic control of a kinase that is deregulated in neurodegeneration.

\section{Discussion}

We demonstrated that CLN6 loss is associated with significant biometal accumulation in the brains of CLN6 affected Merino sheep prior to onset of clinical signs. We observed deregulated metal transporters belonging to the Zip and ZnT families in affected brain regions (Figure 2B-E). Zip7 was the earliest transporter altered, with loss of expression in sucrose density fractions from 3 month-old CLN6 sheep (Figure 3) and in perinatal mouse Cln6 cells (Figure 4B,D). Zip7 was thus the only transporter with altered expression in multiple CLN6 disease models [15], and the only ER-localized metal transporter to be altered. Thus we hypothesized that Zip7 is 


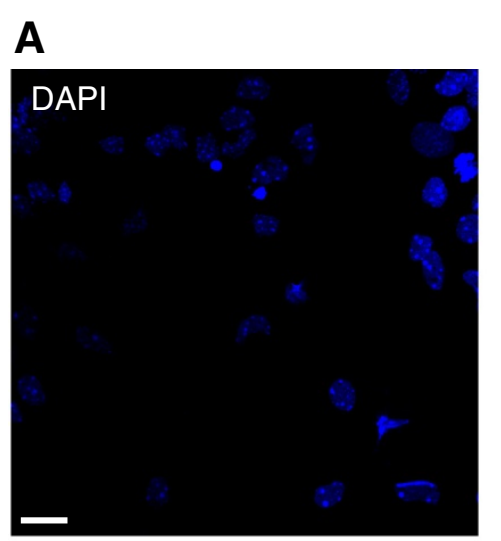

B

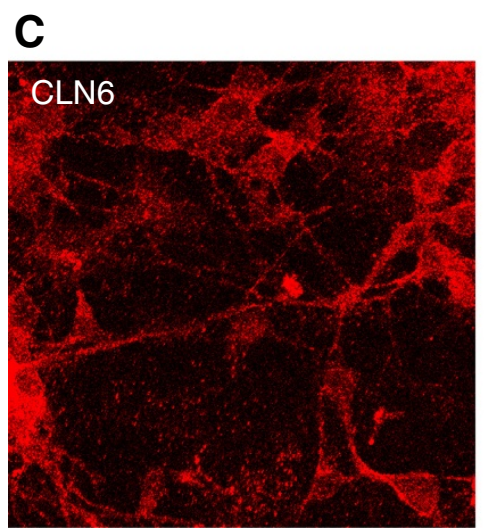

D

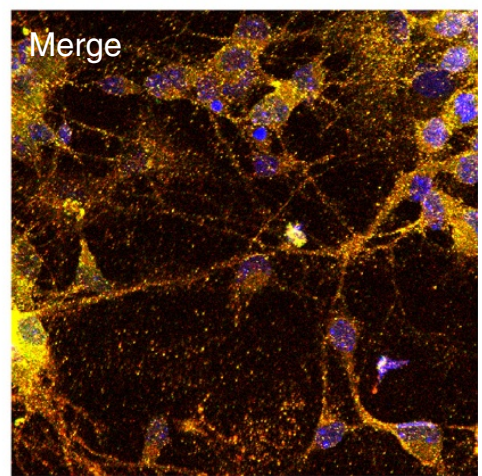

Figure 5 Zip7 co-localizes with CLN6. Primary mouse cortical neurons were reacted with rabbit primary anti-CLN6 and goat primary anti-Zip7 antibodies. Anti-goat AlexaFluor-488 and anti-rabbit AlexaFluor-568 dye labeled secondary antibodies were used to reveal Zip7 and CLN6 expression, respectively. (A) DAPI, (B) Zip7 and (C) CLN6 expression in primary cortical neurons was visualized by confocal microscopy using the Zeiss Meta confocal scanning laser microscope using a magnification of 40X. (D) Overlay images indicate colocalization in punctate structures throughout the cells. Scale bars correspond to $20 \mu \mathrm{m}$.

directly affected by loss of CLN6. Indeed, CLN6 colocalized with Zip7 in murine cortical neurons (Figure 5) and reduced Zip7 expression occurred concomitantly with elevated labile $\mathrm{Zn}$ in primary $\mathrm{Cln} 6$ neurons (Figure 4C). This study implicates Zip7 as a potentially important contributor to NCLs.

Stringent regulation of biometal homeostasis by cellular trafficking systems is critical to prevent metal-induced toxicity. Mn overexposure causes Parkinsonism and $\alpha$ synuclein accumulation [47]. The latter was observed in CLN6 affected sheep (Figure 1B), occurs in another LSD, Gaucher's disease [48], and was recently associated with lysosomal dysfunction in a rare genetic form of parkinsonism, Kufor-Rakeb syndrome, caused by mutations in ATP13a2 [49]. Indeed, mutations, altered expression or aberrant functionality of metal transporters belonging to the ATP7, ATP13, TRMPL and ZnT families has been implicated in neurodegenerative disorders with pathological or clinical similarities to NCLs, and in the LSDs, Niemann-Pick C and Mucolipidosis [50-56]. As increased ATP13a2 expression was reported to rescue lysosomal dysfunction in Parkinson's disease fibroblasts [57], we hypothesise that upregulation of ATP13a2 in CLN6 affected sheep may similarly compensate to partially improve lysosomal function. Together, these studies emphasize that while the precise mechanisms underlying altered metal homeostasis in neurodegeneration are specific for each disease, neurodegenerative processes involving aberrant cellular metal trafficking are intricately linked at the molecular level.

We reported biometal elevation in the brains of 2 CLN6 affected sheep models post-clinical onset [14], and in the brains and heart of presymptomatic $C \ln 6$ mice [15]. Here we show significantly increased concentrations of $\mathrm{Cu}$ and $\mathrm{Zn}$ in the brains of Merino CLN6 affected sheep prior to clinical onset. While the spatio-temporal pattern of metal concentrations is variable in tissues, this is not unexpected for several reasons. As reported for $\mathrm{Cln} 6$ mice, each brain and peripheral tissue region has different localized metal levels, which can vary across disease course [15]. For instance, the stabilization in the levels of $\mathrm{Cu}$ in the brainstem, frontal and parietal lobes observed at 


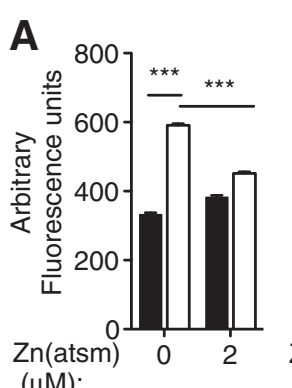

$(\mu \mathrm{M})$ :

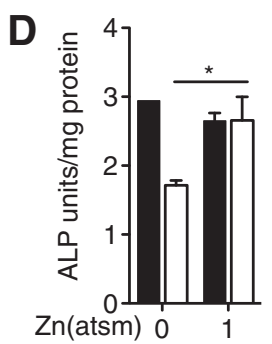
$(\mu \mathrm{M})$ :

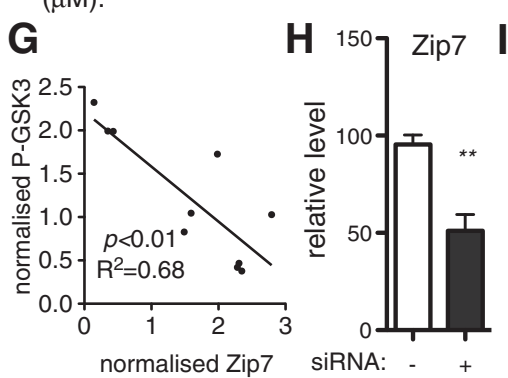

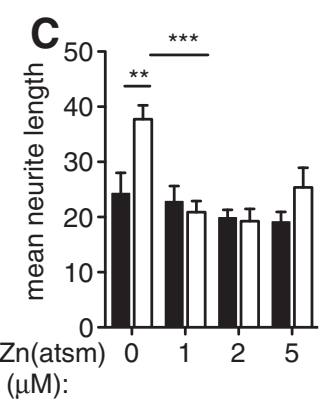
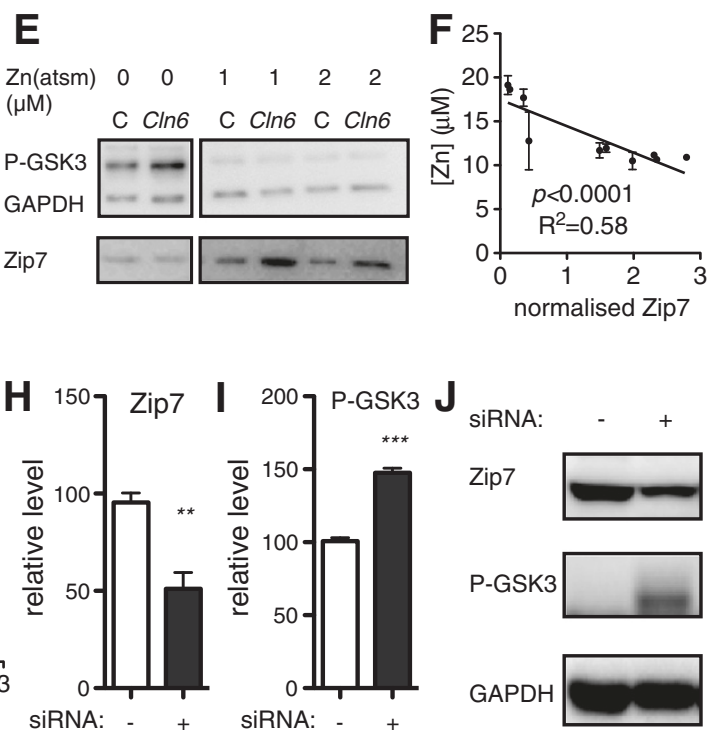

Figure 6 Delivery of bioavailable Zn restores Zn-dependent phenotypes through upregulation of Zip7. (A) Labile Zn in control (black bars throughout) and $\mathrm{Cln} 6$ (white bars throughout) cortical neurons after $1 \mathrm{~h} Z \mathrm{Zn}^{\prime \prime}($ atsm) treatment was measured by FluoZin-3 fluorescence ( $\mathrm{N}=3$ ). (B) MT1A mRNA expression after $1 \mathrm{~h} \mathrm{Zn"(atsm)} \mathrm{treatment} \mathrm{in} \mathrm{cortical} \mathrm{neurons} \mathrm{was} \mathrm{assessed} \mathrm{using} \mathrm{qRT-PCR} \mathrm{(} \mathrm{N}=3)$. (C) Neurite length in control and Cln6 primary cortical neurons treated for $1 \mathrm{~h}$ with $\mathrm{Zn}$ (atsm) was determined by tubulin immunofluorescence. Images (>1,000 cells/well from 4 experiments) were taken using the ArrayScan High Content Platform and analysis was performed using Neuronal Profiling software (refer to Additional file 1). (D) ALP activity in control and Cln6 primary mouse astrocytes was determined after $1 \mathrm{~h} \mathrm{Zn"(atsm)} \mathrm{treatment}(\mathrm{N}=3)$. ( $(\mathrm{E}) \mathrm{Zn}$ " (atsm)-dependent regulation of P-GSK and Zip7 levels after $4 \mathrm{~h}$ treatment was assessed in primary mouse astrocytes by western blotting. Images are from different lanes on the same gel. (F-G) Normalized Zip7 protein levels in Merino sheep occipital lobe were plotted against normalized levels of Zn (F) and P-GSK (G) to determine correlations between these proteins ( $N=3$ sheep per genotype). Linear regression analysis was performed in GraphPad Prism. (H-J) Zip7 knockdown results in hyperphosphorylation of GSK3. 100nM negative control siRNA (-) or Zip7 siRNA (+) was transfected into mouse NIH 3 T3 cells. Zip7 (H) and P-GSK3 (I) protein expression was determined by Western blotting and normalized to expression of GAPDH. Data are expressed as mean + SEM values. ${ }^{*} p<0.05,{ }^{* *} p<0.01,{ }^{* *} p<0.001$ by Student's $t$ test. (J) Images are representative of 3 independent experiments.

7 months (Table 1) parallels a transient improvement in lysosomal function (Figure 1A). This improvement could represent the temporary efficacy of endogenous compensatory mechanisms such as increased MT expression (Figure 2F) that ultimately fail due to presence of persistent stressors, causing animals to succumb to disease by 14 months of age when metal concentrations rise as reported [14]. Moreover, homeostasis of multiple biometals is highly inter-related, and changes in one metal can greatly affect the absorption or trafficking of others in a cell- and tissue-specific manner [58]. It is also important to recognize that, as physiological control of biometal homeostasis is so precise, even subtle focal mislocalisation of biometals can have a critical impact on cell functions, as evident in Alzheimer's disease. Although it is now widely recognized that excess extracellular $\mathrm{Zn}$ and $\mathrm{Cu}$ can promote amyloid $\beta$ aggregation [59] and studies suggest that intracellular metal levels are depleted in Alzheimer's disease [60], these changes are rarely reflected in studies examining metal levels in bulk tissue homogenates [61]. Similarly, the subtly altered metal concentrations here, while indicative of global metal dyshomeostasis, are insufficient to completely capture the impaired subcellular biometal trafficking dynamics. This is further supported by the significant accumulation of $\mathrm{Zn}$ in 3 month-old brains detected in 
sucrose density fractions (Figure 3), but not by bulk analysis. The substantial increase in MT expression (Figure 2F), consistent with a recent report on MT overexpression in LSDs [62], is likely a response to subcellular accumulation of $\mathrm{Zn}$ and/or $\mathrm{Cu}$ in affected brain regions, but overexpressed cytoplasmic MT may not have direct access to effectively sequester mislocalized metal ions. Together these results implicate widespread loss of biometal homeostasis as an early disease feature.

Region-specific early alterations to the CLN6-colocalizing metal transporter, Zip7, in multiple CLN6 disease models indicate an important role of this metal transporter in CLN6 NCL. Visual dysfunction in CLN6 NCL may also be related to Zip7 expression changes, as Zip7 plays a role in brain and eye development in zebrafish [63]. Indeed, Zip7 loss in zebrafish caused eye defects [63], potentially a phenocopy of CLN6 disease. Moreover, loss of the Drosophila Zip7 homologue, Catsup, was recently implicated in amyloid-precursor like protein accumulation [64], providing additional links to Zip7 involvement in neurodegeneration. Analysis of interactions between Zip7 and different mutant forms of CLN6 may shed light on the differences in cellular Zip7 concentrations between mouse and sheep CLN6 models.

Due to high affinity interactions with proteins (as predicted by the Irwing-Williams series), the labile cellular $\mathrm{Zn}$ content is estimated to be in the high picomolar range [65], while ER and Golgi labile $\mathrm{Zn}$ concentrations are kept at a subpicomolar range [66]. Increased compartmentalized labile $\mathrm{Zn}$ as a result of Zip7 loss may give rise to consequential perturbations in the metabolism of other metals. For instance, excess labile Zn may displace redox-active transition metals from metalloproteins, which may participate in Fenton-type ROS-producing reactions. Additionally excess free $\mathrm{Zn}$ in the ER or Golgi may aberrantly bind to, and inhibit, proteins. For instance, $\mathrm{Zn}$ has been shown to inhibit protein tyrosine phosphatases in the ER at low picomolar concentrations [67]. Moreover, Zip7 loss may preclude kinase-dependent $\mathrm{Zn}$ mobilization, termed "Zn wave" signals from being propagated throughout cells [68], which may impact pleiotropic cellular signaling processes.

Further highlighting the role of Zip7 in CLN6 disease, the metal complex, $\mathrm{Zn}^{\mathrm{II}}$ (atsm), restored $\mathrm{Zn}$-dependent functions and induced Zip7 upregulation and GSK3 dephosphorylation in primary $C \ln 6$ cells. $A s \mathrm{Zn}^{\mathrm{II}}($ atsm) is membrane-permeable, delivery of $\mathrm{Zn}$ to intracellular compartments may bypass impaired cellular $\mathrm{Zn}$ trafficking pathways. Labile $\mathrm{Zn}$ accumulation in primary $\mathrm{Cln} 6$ neurons may be restricted to specific subcellular compartments, as previously reported for $C \ln 6$ mouse brains [15], and may therefore not stimulate MT upregulation prior to addition of $\mathrm{Zn}^{\mathrm{II}}$ (atsm). Thus, $\mathrm{Zn}^{\mathrm{II}}$ (atsm) is likely to exert protective effects via a dual mechanism involving combined induction of Zip7 and MT. Zip7 induced by $\mathrm{Zn}^{\mathrm{II}}$ (atsm) may protect cells from toxic accumulation of compartmentalized labile metals by transporting these metals from the ER or Golgi, resulting in normalization of subcellular metal levels. This would promote an increase in bioavailable metals resulting in enhanced activity of Zn-requiring enzymes such as ALP (Figure 6D). Concomitantly, induction of MT is likely to result in MT-dependent sequestration of any excess metals that are liberated from the ER or Golgi in Cln6 cells that are not directly required for enzymatic functions.

\section{Conclusions}

Impaired metal homeostasis is a key hallmark of neurodegenerative disease. Here we show that aberrant biometal functions in CLN6 disease are driven by loss of the metal transporter, Zip7. The protective and metal modulating effects of $\mathrm{Zn}^{\mathrm{II}}$ (atsm) treatment in vitro, coupled with the proven success of metal btsc compounds in improving motor and cognitive functions in neurodegeneration models in vivo [37-39], suggest that $\mathrm{Zn}^{\mathrm{II}}$ (atsm) may be a candidate for NCL therapeutic trials.

\section{Additional files}

\begin{abstract}
Additional file 1: $\mathrm{Zn}^{\text {"I }}$ (atsm) treatment reduces aberrant neurite branching in primary Cln6 cortical neurons. (A) Neurite branching in control (black bars) and Cln6 (white bars) primary cortical neurons treated for $1 \mathrm{~h}$ with $\mathrm{Zn}$ "(atsm) was determined by tubulin immunofluorescence. (B) Representative image of tubulin staining of primary cortical neurons. Images (>1,000 cells/well) were taken using the ArrayScan High Content Platform. (C) Analysis was performed using Neuronal Profiling software. Processed images show nuclei (blue), cell bodies (cyan), neurites (green or magenta for neurites from neighboring neurons for easier identification), branch points (yellow).
\end{abstract}

Additional file 2: Manganese and cobalt concentrations in the tissues of preclinical CLN6 Merino sheep.

Additional file 3: Zip7 concentrations are significantly and progressively reduced in CLN6 sheep. Immunoblots of homogenates $(5 \mu \mathrm{g})$ isolated from the occipital lobe of 3 and 14 month-old control (C) or CLN6 affected sheep ( $N=3-4$ per group) probed with antibodies directed against Zip7. Total ERK was used as a loading control.

Additional file 4: Unaltered metal transporter proteins in Merino CLN6 affected sheep. (A-C) Densitometry and representative immunoblots of homogenates $(5-40 \mu \mathrm{g})$ isolated from the occipital lobe of 3, 7 and 14 month old control or CLN6 affected Merino sheep ( $N=3$ per group) probed with antibodies directed against ZnT1 (A), ZnT3 (B) or ZnT6 (C). GAPDH, $\beta$-tubulin, total Akt or total ERK, as appropriate, were used as loading controls. Quantification was performed in ImageJ and metal transporter levels are expressed relative to those in control sheep at each age. $\mathrm{C}$, control.

Additional file 5: Alterations to metal transporter protein concentrations in South Hampshire CLN6 affected sheep. Densitometry of western blots of homogenates $(5-40 \mu \mathrm{g})$ isolated from the occipital lobe 12-14 month old control or CLN6 affected South Hampshire sheep or CLN5 heterozygote Borderdale sheep probed with antibodies directed against a range of metal transporters. GAPDH was used as a loading control.

Quantification was performed in ImageJ and metal transporter levels are expressed relative to those in control sheep at each age. ${ }^{*} p<0.05,{ }^{* *} p<0.01$ by Student's $t$ test. $\mathrm{C}$, control; $\mathrm{H}$, heterozygote; $\mathrm{A}$, affected. 


\section{Additional file 6: Zip7 loss is region specific in Merino CLN6 affected sheep. Densitometry analyses and representative western blots of Zip7 levels in the frontal lobe (A), parietal lobe (B) thalamus (C), cerebellum (D), brainstem (E), liver (F) and muscle (G) of 3, 7, and 14-month-old control and CLN6 Merino sheep. GAPDH was used as a loading control. Quantitation was performed in ImageJ and metal transporter concentrations are expressed relative to those in control sheep at each age. ${ }^{* *} p<0.01,{ }^{* *} p<0.001$ by Student's $t$ test.}

Additional file 7: Zip7 loss is region specific South Hampshire CLN6 affected sheep. Densitometry of Zip7 western blots in the frontal lobe (A), thalamus (B), cerebellum (C), brainstem (D) in 12-14 month old control or CLN6 affected South Hampshire sheep ( $N=3$ per group) or CLN5 heterozygote Borderdale sheep $(\mathrm{N}=2)$. GAPDH was used as a loading control. Quantification was performed in ImageJ and metal transporter concentrations are expressed relative to those in control sheep at each age. ${ }^{*} p<0.05,{ }^{* *} p<0.01$ by Student's $t$ test. $\mathrm{C}$, control; $\mathrm{H}$, heterozygote; $A$, affected.

\section{Additional file 8: Zip7 co-localizes with ER in primary cortical} neurons. Primary mouse cortical neurons were fixed and stained with goat primary anti-Zip7 and rabbit primary anti-calnexin antibodies. Anti-rabbit AlexaFluor-568 and anti-goat AlexaFluor 488 dye labeled secondary antibodies were used to reveal Zip7 and calnexin expression. Nuclei were stained with DAPI. (A) DAPI, (B) Zip7 and (C) calnexin expression in primary cortical neurons was visualized by confocal microscopy using the Zeiss Meta confocal scanning laser microscope using a magnification of 20x. (D) Overlay images. Scale bars correspond to $20 \mu \mathrm{m}$.

\section{Abbreviations}

ALP: Alkaline phosphatase; CNS: Central nervous system; ER: Endoplasmic reticulum; ICP-MS: Inductively coupled plasma mass-spectrometry; LSD: Iysosomal storage disease; MT: Metallothionein; NCL: Neuronal ceroid lipofuscinosis.

\section{Competing interests}

Patent protection has previously been sought by the University of Melbourne for the use of bis(thiosemicarbazones) for treatment of diseases. ARW and PSD are co-inventors on this patent application PCT/AU2007/ 001792, which is the subject of a commercialization contract between the University and a private company. The company has not funded nor contributed to research described in this manuscript.

\section{Authors' contributions}

AG, ARW and KMK designed research. AG, KMK, CD, JT, SJP, AC, GEL, JM, LB, IV, DM and JRL performed research. AG, IV, ARW and KMK analyzed the data. AG and KMK wrote the paper. ARW, PJC, JRL and JK provided critical revisions of the manuscript. IT, MH, PSD, JLH and SL synthesized reagents and collected sheep tissue samples. All authors read and approved the final manuscript.

\section{Acknowledgements}

We thank Dr Sara Mole and Sophia Kleine Holthaus, University College, London, for the CLN6 antibody; Professor David Palmer, Faculty of Agriculture and Life Sciences, Lincoln University, New Zealand for the CLN6 affected South Hampshire samples and Dr. Susan Piripi for assisting in collection of Merino samples. Cellomics neurite growth experiments were performed at the MHTP High Content Screening Centre with the assistance of Dr. Trevor Wilson. This work was supported by The Sigrid Juselius Foundation, the Academy of Finland, the Australian Research Council (ARC), and the National Health and Medical Research Council of Australia (NHMRC). ARW is a recipient of an ARC Future Fellowship. The funding sources had no influence in study design; collection, analysis, and interpretation of data; writing the report; or the decision to submit the report for publication.

\section{Author details}

'Department of Pathology, The University of Melbourne, Parkville, VIC 3010, Australia. ${ }^{2} \mathrm{Al}$ Virtanen Institute for Molecular Sciences, University of Eastern Finland, Kuopio Fl-70211, Finland. ${ }^{3}$ Florey Institute of Neuroscience and Mental Health, The University of Melbourne, Parkville, VIC 3010, Australia. ${ }^{4}$ School of Chemistry and Bio21 Molecular Science and Biotechnology Institute, The University of Melbourne, Parkville, VIC 3010, Australia.
${ }^{5}$ ReproGen, Faculty of Veterinary Science, The University of Sydney, Camden, NSW 2570, Australia.

Received: 10 January 2014 Accepted: 19 February 2014 Published: 28 February 2014

\section{References}

1. Bolognin S, Messori L, Zatta P: Metal ion physiopathology in neurodegenerative disorders. Neuromolecular Med 2009, 11:223-238.

2. Larner F, Sampson B, Rehkamper M, Weiss DJ, Dainty JR, O'Riordan S, Panetta T, Bain PG: High precision isotope measurements reveal poor control of copper metabolism in parkinsonism. Metallomics 2013, 5:125-132.

3. Kousi M, Lehesjoki AE, Mole SE: Update of the mutation spectrum and clinical correlations of over 360 mutations in eight genes that underlie the neuronal ceroid lipofuscinoses. Hum Mutat 2012, 33:42-63.

4. Chen R, Fearnley IM, Palmer DN, Walker JE: Lysine 43 is trimethylated in subunit C from bovine mitochondrial ATP synthase and in storage bodies associated with batten disease. J Biol Chem 2004, 279:21883-21887.

5. Haltia M: The neuronal ceroid-lipofuscinoses: from past to present. Biochimica Et Biophysica Acta 2006, 1762:850-856.

6. Mole SE, Williams RE, Goebel HH: The neuronal ceroid lipofuscinoses (batten disease). 2nd edition. England: Oxford University Press; 2011.

7. Bras J, Verloes A, Schneider SA, Mole SE, Guerreiro RJ: Mutation of the parkinsonism gene ATP13A2 causes neuronal ceroid-lipofuscinosis. Hum Mol Genet 2012, 21:2646-2650

8. Farias FH, Zeng R, Johnson GS, Wininger FA, Taylor JF, Schnabel RD, McKay SD, Sanders DN, Lohi H, Seppala EH, Wade CM, Lindblad-Toh K, O'Brien DP, Katz ML: A truncating mutation in ATP13A2 is responsible for adult-onset neuronal ceroid lipofuscinosis in Tibetan terriers. Neurobiol Dis 2011, 42:468-474.

9. Ramirez A, Heimbach A, Grundemann J, Stiller B, Hampshire D, Cid LP, Goebel I, Mubaidin AF, Wriekat AL, Roeper J, Al-Din A, Hillmer AM, Karsak M, Liss B, Woods CG, Behrens MI, Kubisch C: Hereditary parkinsonism with dementia is caused by mutations in ATP13A2, encoding a lysosomal type 5 P-type ATPase. Nat Genet 2006, 38:1184-1191.

10. Schultheis PJ, Fleming SM, Clippinger AK, Lewis J, Tsunemi T, Giasson B, Dickson DW, Mazzulli JR, Bardgett ME, Haik KL, Ekhator O, Chava AK, Howard J, Gannon M, Hoffman E, Chen Y, Prasad V, Linn SC, Tamargo RJ, Westbroek W, Sidransky E, Krainc D, Shull GE: Atp13a2-Deficient Mice Exhibit Neuronal Ceroid Lipofuscinosis, Limited alpha-Synuclein Accumulation, and Age-Dependent Sensorimotor Deficits. Hum Mol Genet 2013, 22(10):2067-2082.

11. Wohlke A, Philipp U, Bock P, Beineke A, Lichtner P, Meitinger T, Distl O: A one base pair deletion in the canine ATP13A2 gene causes exon skipping and late-onset neuronal ceroid lipofuscinosis in the Tibetan terrier. PLoS Genet 2011, 7:e1002304.

12. Arsov T, Smith KR, Damiano J, Franceschetti S, Canafoglia L, Bromhead CJ, Andermann E, Vears DF, Cossette P, Rajagopalan S, McDougall A, Sofia V, Farrell M, Aguglia U, Zini A, Meletti S, Morbin M, Mullen S, Andermann F, Mole SE, Bahlo M, Berkovic SF: Kufs disease, the major adult form of neuronal ceroid lipofuscinosis, caused by mutations in CLN6. Am J Hum Genet 2011, 88:566-573.

13. Heine C, Koch B, Storch S, Kohlschutter A, Palmer DN, Braulke T: Defective endoplasmic reticulum-resident membrane protein CLN6 affects lysosomal degradation of endocytosed arylsulfatase A. J Biol Chem 2004, 279:22347-22352.

14. Kanninen KM, Grubman A, Meyerowitz J, Duncan C, Tan JL, Parker SJ, Crouch PJ, Paterson BM, Hickey JL, Donnelly PS, Volitakis I, Tammen I, Palmer DN, White AR: Increased zinc and manganese in parallel with neurodegeneration, synaptic protein changes and activation of Akt/ GSK3 signaling in ovine CLN6 neuronal ceroid lipofuscinosis. PLOS One 2013, 8:e58644.

15. Kanninen KM, Grubman A, Caragounis A, Duncan C, Parker SJ, Lidgerwood GE, Volitakis I, Ganio G, Crouch PJ, White AR: Altered biometal homeostasis is associated with CLN6 mRNA loss in mouse neuronal ceroid lipofuscinosis. Biol Open 2013, 2:635-646.

16. Tammen I, Cook RW, Nicholas FW, Raadsma HW: Neuronal ceroid lipofuscinosis in Australian Merino sheep: a new animal model. Eur $\mathrm{J}$ Paediatr Neurol 2001, 5(Suppl A):37-41.

17. Cook RW, Jolly RD, Palmer DN, Tammen I, Broom MF, McKinnon R: Neuronal ceroid lipofuscinosis in Merino sheep. Aust Vet J 2002, 80:292-297. 
18. Tammen I, Houweling PJ, Frugier T, Mitchell NL, Kay GW, Cavanagh JA, Cook RW, Raadsma HW, Palmer DN: A missense mutation (c.184C > T) in ovine CLN6 causes neuronal ceroid lipofuscinosis in Merino sheep whereas affected South Hampshire sheep have reduced levels of CLN6 mRNA. Biochimica Et Biophysica Acta 2006, 1762:898-905.

19. Frugier T, Mitchell NL, Tammen I, Houweling PJ, Arthur DG, Kay GW, van Diggelen OP, Jolly RD, Palmer DN: A new large animal model of CLN5 neuronal ceroid lipofuscinosis in Borderdale sheep is caused by a nucleotide substitution at a consensus splice site (c.571+1G $>$ A) leading to excision of exon 3. Neurobiol Dis 2008, 29:306-315.

20. Bronson RT, Donahue LR, Johnson KR, Tanner A, Lane PW, Faust JR: Neuronal ceroid lipofuscinosis (nclf), a new disorder of the mouse linked to chromosome 9. Am J Med Genet 1998, 77:289-297.

21. Liddell JR, Hoepken HH, Crack PJ, Robinson SR, Dringen R: Glutathione peroxidase 1 and glutathione are required to protect mouse astrocytes from iron-mediated hydrogen peroxide toxicity. J Neurosci Res 2006, 84:578-586.

22. Greenough MA, Volitakis I, Li QX, Laughton K, Evin G, Ho M, Dalziel AH, Camakaris J, Bush Al: Presenilins promote the cellular uptake of copper and zinc and maintain copper chaperone of SOD1-dependent copper/ zinc superoxide dismutase activity. J Biol Chem 2011, 286:9776-9786.

23. Dayal D, Palanimuthu D, Shinde SV, Somasundaram K, Samuelson AG: A novel zinc bis(thiosemicarbazone) complex for live cell imaging. J Biol Inorg Chem 2011, 16:621-632

24. Radio NM, Breier JM, Shafer TJ, Mundy WR: Assessment of chemical effects on neurite outgrowth in PC12 cells using high content screening. Toxicol Sci 2008, 105:106-118.

25. Radio NM, Mundy WR: Developmental neurotoxicity testing in vitro: models for assessing chemical effects on neurite outgrowth. Neurotoxicology 2008, 29:361-376.

26. Chen H, Shalom-Feuerstein R, Riley J, Zhang SD, Tucci P, Agostini M, Aberdam D, Knight RA, Genchi G, Nicotera P, Melino G, Vasa-Nicotera M: miR-7 and miR-214 are specifically expressed during neuroblastoma differentiation, cortical development and embryonic stem cells differentiation, and control neurite outgrowth in vitro. Biochem Bioph Res Co 2010, 394:921-927.

27. Parker SJ, Meyerowitz J, James JL, Liddell JR, Nonaka T, Hasegawa M, Kanninen KM, Lim S, Paterson BM, Donnelly PS, Crouch PJ, White AR Inhibition of TDP-43 accumulation by bis(thiosemicarbazonato)-copper complexes. PloS One 2012, 7:e42277.

28. Oswald MJ, Palmer DN, Kay GW, Shemilt SJ, Rezaie P, Cooper JD: Glial activation spreads from specific cerebral foci and precedes neurodegeneration in presymptomatic ovine neuronal ceroid lipofuscinosis (CLN6). Neurobiol Dis 2005, 20:49-63.

29. Mindell JA: Lysosomal acidification mechanisms. Annu Rev Physiol 2012 74:69-86.

30. Tong J, Wong H, Guttman M, Ang LC, Forno LS, Shimadzu M, Rajput AH, Muenter MD, Kish SJ, Hornykiewicz O, Furukawa Y: Brain alpha-synuclein accumulation in multiple system atrophy, Parkinson's disease and progressive supranuclear palsy: a comparative investigation. Brain 2010, 133:172-188.

31. Antala S, Dempski RE: The human ZIP4 transporter has two distinct binding affinities and mediates transport of multiple transition metals. Biochemistry 2012, 51:963-973.

32. Dempski RE: The cation selectivity of the ZIP transporters. Curr Top Membr 2012, 69:221-245.

33. Nam H, Knutson MD: Effect of dietary iron deficiency and overload on the expression of ZIP metal-ion transporters in rat liver. Biometals 2012, 25:115-124.

34. Pinilla-Tenas JJ, Sparkman BK, Shawki A, Illing AC, Mitchell CJ, Zhao N, Liuzzi JP, Cousins RJ, Knutson MD, Mackenzie B: Zip14 is a complex broad-scope metal-ion transporter whose functional properties support roles in the cellular uptake of zinc and nontransferrin-bound iron. Am J Physiol Cell Physiol 2011, 301:C862-C871.

35. Wang CY, Jenkitkasemwong S, Duarte S, Sparkman BK, Shawki A, Mackenzie B, Knutson MD: ZIP8 is an iron and zinc transporter whose cell-surface expression is up-regulated by cellular iron loading. J Biol Chem 2012, 287:34032-34043.

36. Taylor KM, Morgan HE, Johnson A, Nicholson Rl: Structure-function analysis of HKE4, a member of the new LIV-1 subfamily of zinc transporters. Biochem J 2004, 377:131-139.

37. Crouch PJ, Hung LW, Adlard PA, Cortes M, Lal V, Filiz G, Perez KA, Nurjono M, Caragounis A, Du T, Laughton K, Volitakis I, Bush Al, Li QX, Masters CL,
Cappai R, Cherny RA, Donnelly PS, White AR, Barnham KJ: Increasing Cu bioavailability inhibits Abeta oligomers and tau phosphorylation. Proc Natl Acad Sci U S A 2009, 106:381-386.

38. Hung LW, Villemagne VL, Cheng L, Sherratt NA, Ayton S, White AR, Crouch PJ, Lim S, Leong SL, Wilkins S, George J, Roberts BR, Pham CL, Liu X, Chiu FC, Shackleford DM, Powell AK, Masters CL, Bush Al, O'Keefe G, Culvenor JG, Cappai R, Cherny RA, Donnelly PS, Hill AF, Finkelstein DI, Barnham KJ: The hypoxia imaging agent Cull(atsm) is neuroprotective and improves motor and cognitive functions in multiple animal models of Parkinson's disease. J Exp Med 2012, 209:837-854.

39. Soon CP, Donnelly PS, Turner BJ, Hung LW, Crouch PJ, Sherratt NA, Tan JL, Lim NK, Lam L, Bica L, Lim S, Hickey JL, Morizzi J, Powell A, Finkelstein DI, Culvenor JG, Masters CL, Duce J, White AR, Barnham KJ, Li QX: Diacetylbis(N (4)-methylthiosemicarbazonato) copper(II) (Cull(atsm)) protects against peroxynitrite-induced nitrosative damage and prolongs survival in amyotrophic lateral sclerosis mouse model. J Biol Chem 2011, 286:44035-44044.

40. Donnelly PS, Caragounis A, Du T, Laughton KM, Volitakis I, Cherny RA, Sharples RA, Hill AF, Li QX, Masters CL, Barnham KJ, White AR: Selective intracellular release of copper and zinc ions from bis (thiosemicarbazonato) complexes reduces levels of Alzheimer disease amyloid-beta peptide. J Biol Chem 2008, 283:4568-4577.

41. Lehman LD, Poisner AM: Induction of metallothionein synthesis in cultured human trophoblasts by cadmium and zinc. J Toxicol Environ Health 1984, 14:419-432.

42. Adlard PA, Bica L, White AR, Nurjono M, Filiz G, Crouch PJ, Donnelly PS, Cappai R, Finkelstein DI, Bush Al: Metal ionophore treatment restores dendritic spine density and synaptic protein levels in a mouse model of Alzheimer's disease. PLoS One 2011, 6:e17669.

43. Kay GW, Palmer DN, Rezaie P, Cooper JD: Activation of non-neuronal cells within the prenatal developing brain of sheep with neuronal ceroid lipofuscinosis. Brain Pathol 2006, 16:110-116.

44. Thelen M, Damme M, Schweizer M, Hagel C, Wong AM, Cooper JD, Braulke T, Galliciotti G: Disruption of the autophagy-lysosome pathway is involved in neuropathology of the nclf mouse model of neuronal ceroid lipofuscinosis. PLoS One 2012, 7:e35493.

45. Suzuki T, Ishihara K, Migaki H, Matsuura W, Kohda A, Okumura K, Nagao M, Yamaguchi-Iwai Y, Kambe T: Zinc transporters, ZnT5 and ZnT7, are required for the activation of alkaline phosphatases, zinc-requiring enzymes that are glycosylphosphatidylinositol-anchored to the cytoplasmic membrane. J Biol Chem 2005, 280:637-643.

46. Min YK, Lee JE, Chung KC: Zinc induces cell death in immortalized embryonic hippocampal cells via activation of Akt-GSK-3beta signaling. Exp Cell Res 2007, 313:312-321.

47. Verina T, Schneider JS, Guilarte TR: Manganese exposure induces alphasynuclein aggregation in the frontal cortex of non-human primates. Toxicol Lett 2013, 217:177-183.

48. Neumann J, Bras J, Deas E, O'Sullivan SS, Parkkinen L, Lachmann RH, Li A Holton J, Guerreiro R, Paudel R, Segarane B, Singleton A, Lees A, Hardy J, Houlden H, Revesz T, Wood NW: Glucocerebrosidase mutations in clinical and pathologically proven Parkinson's disease. Brain: J Neurol 2009, 132:783-1794.

49. Tsunemi T, Krainc D: Zn2+ dyshomeostasis caused by loss of ATP13A2/ PARK9 leads to lysosomal dysfunction and alpha-synuclein accumulation. Hum Mol Genet 2013. Published online Dec 2013; PMID: 24334770.

50. Chelly J, Monaco AP: Cloning the Wilson disease gene. Nat Genet 1993, 5:317-318.

51. Chelly J, Tumer Z, Tonnesen T, Petterson A, Ishikawa-Brush Y, Tommerup N, Horn N, Monaco AP: Isolation of a candidate gene for Menkes disease that encodes a potential heavy metal binding protein. Nat Genet 1993, 3:14-19.

52. Kiselyov K, Colletti GA, Terwilliger A, Ketchum K, Lyons CW, Quinn J, Muallem S: TRPML: transporters of metals in lysosomes essential for cell survival? Cell Calcium 2011, 50:288-294.

53. Lovell MA, Smith $J$, Xiong S, Markesbery WR: Alterations in zinc transporter protein-1 (ZnT-1) in the brain of subjects with mild cognitive impairment, early, and late-stage Alzheimer's disease. Neurotox Res 2005, 7:265-271.

54. Lyubartseva G, Smith JL, Markesbery WR, Lovell MA: Alterations of zinc transporter proteins ZnT-1, ZnT-4 and ZnT-6 in preclinical Alzheimer's disease brain. Brain Pathol 2010, 20:343-350.

55. Quadri M, Federico A, Zhao T, Breedveld GJ, Battisti C, Delnooz C, Severijnen LA, Di Toro Mammarella L, Mignarri A, Monti L, Sanna A, Lu P, Punzo F, 
Cossu G, Willemsen R, Rasi F, Oostra BA, van de Warrenburg BP, Bonifati V: Mutations in SLC30A10 cause parkinsonism and dystonia with hypermanganesemia, polycythemia, and chronic liver disease. Am J Hum Genet 2012, 90:467-477.

56. Shen D, Wang X, Li X, Zhang X, Yao Z, Dibble S, Dong XP, Yu T, Lieberman AP, Showalter HD, Xu H: Lipid storage disorders block lysosomal trafficking by inhibiting a TRP channel and lysosomal calcium release. Nat Commun 2012, 3:731.

57. Dehay B, Ramirez A, Martinez-Vicente M, Perier C, Canron MH, Doudnikoff E, Vital A, Vila M, Klein C, Bezard E: Loss of P-type ATPase ATP13A2/PARK9 function induces general lysosomal deficiency and leads to Parkinson disease neurodegeneration. Proc Natl Acad Sci U S A 2012, 109:9611-9616.

58. Bolognin S, Pasqualetto F, Mucignat-Caretta C, Scancar J, Milacic R, Zambenedetti P, Cozzi B, Zatta P: Effects of a copper-deficient diet on the biochemistry, neural morphology and behavior of aged mice. PLoS One 2012, 7:e47063.

59. Barnham KJ, Haeffner F, Ciccotosto GD, Curtain CC, Tew D, Mavros C, Beyreuther K, Carrington D, Masters CL, Cherny RA, Cappai R, Bush Al: Tyrosine gated electron transfer is key to the toxic mechanism of Alzheimer's disease beta-amyloid. FASEB J 2004, 18:1427-1429.

60. Adlard PA, Parncutt JM, Finkelstein DI, Bush Al: Cognitive loss in zinc transporter-3 knock-out mice: a phenocopy for the synaptic and memory deficits of Alzheimer's disease? J Neurosci 2010, 30:1631-1636.

61. Schrag M, Mueller C, Oyoyo U, Smith MA, Kirsch WM: Iron, zinc and copper in the Alzheimer's disease brain: a quantitative meta-analysis. Some insight on the influence of citation bias on scientific opinion. Prog Neurobiol 2011, 94:296-306.

62. Cesani M, Cavalca E, Macco R, Leoncini G, Terreni MR, Lorioli L, Furlan R, Comi G, Doglioni C, Zacchetti D, Sessa M, Scherzer CR, Biffi A:

Metallothioneins as dynamic markers for brain disease in lysosomal disorders. Ann Neurol 2013, 75(1):127-137.

63. Yan G, Zhang Y, Yu J, Yu Y, Zhang F, Zhang Z, Wu A, Yan X, Zhou Y, Wang F: Slc39a7/zip7 plays a critical role in development and zinc homeostasis in zebrafish. PLoS One 2012, 7:e42939.

64. Groth C, Sasamura T, Khanna MR, Whitley M, Fortini ME: Protein trafficking abnormalities in Drosophila tissues with impaired activity of the ZIP7 zinc transporter Catsup. Development 2013, 140:3018-3027.

65. Colvin RA, Bush Al, Volitakis I, Fontaine CP, Thomas D, Kikuchi K, Holmes WR Insights into $\mathrm{Zn2}$ homeostasis in neurons from experimental and modeling studies. Am J Physiol Cell Physiol 2008, 294:C726-C742.

66. Qin Y, Dittmer PJ, Park JG, Jansen KB, Palmer AE: Measuring steady-state and dynamic endoplasmic reticulum and Golgi $\mathrm{Zn} 2+$ with genetically encoded sensors. Proc Natl Acad Sci U S A 2011, 108:7351-7356.

67. Wilson M, Hogstrand C, Maret W: Picomolar concentrations of free zinc(II) ions regulate receptor protein-tyrosine phosphatase beta activity. J Biol Chem 2012, 287:9322-9326.

68. Taylor KM, Hiscox S, Nicholson Rl, Hogstrand C, Kille P: Protein kinase CK2 triggers cytosolic zinc signaling pathways by phosphorylation of zinc channel ZIP7. Sci Signal 2012, 5:ra11.

doi:10.1186/2051-5960-2-25

Cite this article as: Grubman et al:: Deregulation of subcellular biometal homeostasis through loss of the metal transporter, Zip7, in a childhood neurodegenerative disorder. Acta Neuropathologica Communications 2014 2:25.

\section{Submit your next manuscript to BioMed Central and take full advantage of:}

- Convenient online submission

- Thorough peer review

- No space constraints or color figure charges

- Immediate publication on acceptance

- Inclusion in PubMed, CAS, Scopus and Google Scholar

- Research which is freely available for redistribution 